\title{
HANDICAPPED CHILDREN: EMOTIONAL DEVELOPMENT AND ROLE OF THERAPIST
}

R. S. JACOBSON, B.Sc. Physiotherapy (Witwatersrand), D.S.E., Cerebral Palsy (U.N.I.S.A.), M.A. Clin Psych. (Witwatersrand)

G. STRAKER, Ph.D. (Witwatersrand)

\section{SUMMARY}

The development of trust, pride and autonomy, initiative and industry in the first ten years of childhood is described. The problems encountered by the handicapped child and his parents are pointed out. The rôle the therapist can play and the selfknowledge necessary for this rôle are briefly discussed.

This paper is aimed at promoting an understanding of the emotional world and the developmental tasks cing the physically handicapped child. A discussion this nature is necessary for the following reasons:

Firstly, there is a consistent finding in the literature that a child's emotional development, behaviour and reaction to his handicap are not dependant upon the extent of the handicap itself, but upon his emotional adjustment to it (Freeman, 1967).

Secondly, the authors are of the opinion that, during the early months after the diagnosis of the handicap, it is of considerable importance for both mother and father to have ongoing emotional as well as medical support. The physiotherapist who has contact with the child may find herself in a position where she has to help the mother contain her feelings of uncertainty, unsureness and insecurity at each stage of the child's maturation. In order to do this, a physiotherapist must have an ability to empathise with the plight of the parents, without becoming 'sucked' into the family system, as well as a basic knowledge of the emotional tasks the child must negotiate.

\section{DEVELOPMENTAL TASKS}

Any child is part of two simultaneously functioning worlds; the world of adults and that of his peers. The physically handicapped child is necessarily dependent upon adults for a period of time that far exceeds that of his normal counterpart. The primary focus of this paper will be on the relevant aspects of normal delopment that occur within the adult world of the Mld. Special reference will be made to the part played by the physiotherapist.

Despite this narrow structure, it is necessary to recognise that motor, sensory, perceptual, cognitive, language, social and emotional development all go hand in hand and cannot be isolated from one another. Impairment in any area can affect overall development.

In addition to the above, it must be stressed that

\section{OPSOMMING}

Die ontwikkeling van vertroue, trots en outonomie, inisiatief en vlyt in die eerste tien kinderjare word beskryf. Die probleme wat deur die gestremde kind en sy ouers teëgekom word, word uitgewys. Die rol wat die terapeut kan speel en die selfkennis benodig vir diè rol word kortliks bespreek.

negotiation of any emotional crises for the handicapped child must be even more hazardous in a world that admires physical health and emphasises normality. The child, as well as significant adults in his world (including therapists), must deal with the fact that he is neither healthy nor totally normal. Bearing this in mind, let us now examine the possible vulnerable areas in the emotional development of the handicapped child. The framework adopted for this discussion of development from birth to ten years is that of Erik Erikson. Although in his book Childhood and Society (1955) Erikson dealt extensively with developmental crises from birth through to old age, it is beyond the scope of the present paper either to discuss all these stages or to deal with them comprehensively. Thus, only a brief outline of the stages from birth to ten years of age will be mentioned below.

The four basic developmental tasks of childhood are the development of basic trust, pride and autonomy, initiative and finally industry (Erikson, 1955). Within the first year of life the mother creates a sense of trust in the child by sensitively and consistently caring for and responding to the baby's physical and emotional needs. Parents must not only have ways of satisfying the child, but also convey to the child a conviction that they "know" how to handle and care for their new-born baby. In the case of the physically handicapped child, the parents may not be able to cater for the child in this way. This may be because the handicapped child may show alterations of development that may be confusing and frightening for the parent e.g. opisthotonus or feeding problems. The mother of the handicapped child may therefore not be as sensitive or as sure in the handling of her child. The child may begin to experience the world as painful, chaotic and capricious. The ability to trust the world and particularly significant adults may therefore be impaired in the physically handicapped child and the end result may be a child who is mistrustful of people and

\section{Contents - Inhoud}

Handicapped Children: Emotional Development and Role of Therapist - R. S. Jacobson and G. $\begin{array}{llllllllllllll}\text { Straker } & \ldots & \ldots & \ldots & \ldots & \ldots & \ldots & \ldots & \ldots & \ldots & \ldots & \ldots & \ldots\end{array}$ Play in :Inifancy and Application in Treatment -

D. Courlander

Acupuncture - An Investigation - H. C. Watts Ethics in Human Experimentation - J. C. $\begin{array}{lllllllllll}\text { Beenhakker } & \ldots & \ldots & \ldots & \ldots & \ldots & \ldots & \ldots & \ldots & \ldots & \ldots\end{array}$ Treatment Note - A Plea for Massage -

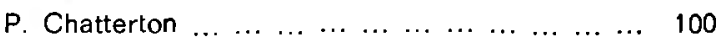

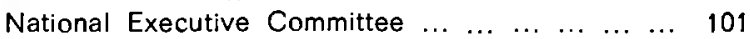

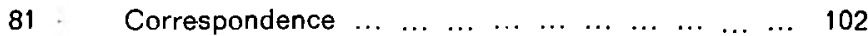

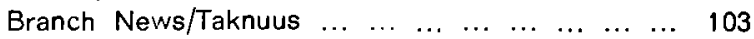

News from Special Interest Groups ... ... ... ... 105

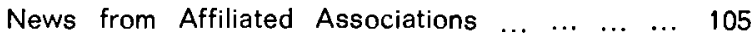

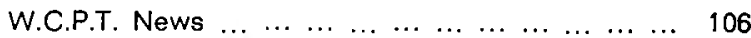

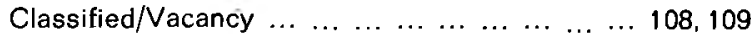

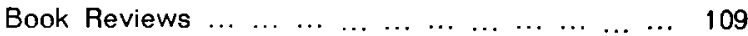


situations. This is commonly seen in the excessively demanding, insecure and testing behaviour of these children. Early supportive help for the mother of any handicapped child therefore is not a luxury but a necessity.

Later in the first year of life the mother helps the normal child to deal with frustration and so the child develops the ability to delay immediate gratification of all his needs. In so doing, the child develops his own resources for dealing with future frustrations. The parents of a handicapped child may not be able to provide the child with situations where he will learn to deal with frustration. Although the parents of the handicapped child may be acting out of feelings of guilt, overprotectiveness or anxiety, the end point is a child who cannot tolerate any frustration whatsoever. This can be seen in the child who demands immediate satisfaction of his every whim and who throws severe and frightening temper tantrums. Here the professional can help parents deal with their own anxieties. With excessive anxiety under control and with empathic support, the parents of the handicapped child will be more able to provide "optimal" frustration for their baby. In addition to increasing his frustration tolerance, the ten month old normal baby is dealing with the anxiety that ensues from separating from his parents. The average parent deals with this by briefly separating from the child, never allowing the production of an overwhelming anxiety in the child. The normal child thus learns to trust the parents' comings and goings, so laying the groundwork for the separation that occurs when the child becomes school-going. The handicapped child, due to his extended and excessive dependency needs, may not be subjected to normal separations from the parents. The parents, due to overprotectiveness, guilt and anxiety may not allow the child to experience short separations and the handicapped child may learn to control the parents' comings and goings. A vicious circle is set up as the restraint placed on the parents leads to resentment and annoyance in the parent. The child may pick up these feelings of resentment and this triggers feelings of insecurity in the child which in turn may lead to increased efforts on his part to make his parents conform to his demands. Parents of handicapped children need guidance at a very early stage in dealing with their own anxiety at separating for short periods from their child. Therapists should be able to deal with this issue. On the other hand, many handicapped children are subjected to long separations from parents by numerous hospitalisations. The overwhelming anxiety produced on such occasions may prevent a child from mastering this developmental task. Careful consideration should therefore be given before hospitalising a young child without its mother.

In sum, the handicapped child may experience, within the first year of life, many interferences with his ability to form trusting relationships - trust not only of significant others but also of himself.

The second year of life is the period during which the child is establishing his own sense of autonomy i.e. he repeatedly attempts to establish control of his own bodily functions. Erikson (1955) draws our attention to an important issue: "As his environment encourages him to 'stand on his own feet', it must protect him against meaningless and arbitrary experiences of shame and early doubt" (p. 244). In light of this statement, it is the authors' view that this stage of development is particularly difficult for the handicapped child. This is because the body of the handicapped child may become a supervised object for others who may subject it to constant observation and exercise absolute right over it. In any attempt to improve the child's functioning marginally, both parents and therapists may drive the child continuously, so promoting an attitude of submission, dependence and passivity. It is at this point that therapists need to evaluate their aims, programmes and relationship with the child. The child must be allowed to experience autonomy over his own body by being allowed the freedom to explore his environment without the constant "supervision" of his movements. Thus the importance of allowing the child to experience normal movement is the aim of therapy, not the constant verbal correction of posture or movement.

In the early pre-school years (3-6 years) the child must negotiate another developmental crisis viz. the child must 'grow together' both in his person and his body. At this stage the child forgets failures quickly and tries again and again to succeed at various tasks. Thus the sense of initiative adds a quality of being active and task-involved to the sense of autonomy developed in the previous stage. The handicapped child faced with problems gives up and so does not develop. the sense of initiative. Often it is easier for paren 6 and child if adults complete the tasks rather tha allow the child to go through repeated failures. In order to negotiate this stage, the therapist needs to aspess the child's capabilities comprehensively and advise the parents in the presentation of challenging tasks which are not beyond the child's abilities. Success and challenge are important at this stage for any child.

At the same time, the child is moving more into the world of his peers. Peer interaction has been cited (Hartup, 1967) as an essential part of the socialisation process and socialisation is one of the major aims of habilitation of the handicapped. Hartup goes even further in stating that a child who does not fit comfortably into interaction with his peers is indeed at risk of emotional maladjustment. Peer interaction at this stage usually occurs through the medium of play. The importance of play for all children is being underlined in the literature of all schools of psychology (Singer, 1975; Singer \& Singer, 1976). Failure to play and socialise with peers may contribute to anxiety in social situations, excessive aggression and lack of strong emotional ties to others. Many times the play of the handicapped child is replaced by adult-supervised "constructive activities". Socialisation and play with peers may be a restricted area for the handicapped child. In working with parents, therapists should find ways to provide play experience. Research with regard to play and peer interaction amongst handicapped childr? is needed.

The normal child, at this stage, is commonly experiencing transient fears which are usually of no pathological significance. However, the handicapped child may develop multiple and persistent fears which are heavily imbued with anxiety. This anxiety may manifest itself in dreams and nightmares with central themes of persecution, abandonment and mutilation which indicate the impact of the handicap not only upon the child's inter- and intra-personal life but also upon his body image. Caught in these fantasies, the child may try to make sense of his handicap by constructing fantasies, often based on his own wrong doing. The importance of referral for psychological help cannot be understated in situations such as these.

By the time the normal child reaches primary school, he should have established trusting relationships, have a sense of autonomy and demonstrate initiative and interest in his environment. A further developmental task which the child must accomplish at this age is that of establishing a sense of adequacy and industry. The sense of industry is usually cultivated within the milieu of formal schooling. Formal schooling also re- 
quiries that less allowance be made for the individual child who must now fit into group activities and obey group rules. In other words, the child must be aware of and respect the wishes of others. This cannot be accomplished without previous peer participation which provides a child with opportunities to learn the consequences of his own actions. As already mentioned, the handicapped child may not have interacted successfully with his peers and thus adjustment to formal schooling may be difficult. The choice of ordinary or special school is a particularly stressful decision for many parents of handicapped children. The major issue that needs evaluation is that the child be placed in a situation where he will experience reasonable success and acceptance from his peers. The other psychological sequelae of physical handicap, viz, learning problems and difficulties with abstract thought have been well documented elsewhere (Rutter, Graham \& Yule, 1970).

To summarise, the emotional development of any handicapped child is especially vulnerable. It is important that all professional workers dealing with the ahild view him as a WHOLE dynamic individual. There re some salient factors which commonly prevent therapists from viewing the child objectively. What these factors may be has as yet not been empirically researched. However one may make informed guesses as to what could prevent therapists from viewing handicapped children objectively. What follows is based on many years of experience of the senior author as a therapist at a school for cerebral palsied children.

Therapists may be unaware of, and tend to deny, their own feelings when working with the handicapped. "Rescue fantasies" may easily develop in therapists with a need to feel superior to parents and other workers. If the therapist is unaware of her own feelings, she may do the child and family a great disservice by not allowing them to come to terms with the limits of professional help and ultimately the disability itself. Therapists can promote the belief in parents that the child can become normal or nearly so and this must be guarded against. The parents must be supported and helped gently to see reality - not to hope for the impossible.

Therapists also need to recognise that feelings of anger and disgust may be problems not only for the parents of the handicapped child but also for themselves. In our culture these feelings are regarded as unacceptable but they are just as natural as positive feelings. Often these angry feelings may be transferred onto a particular therapist or institution. The therapist must understand the dynamics involved, refrain from retaliation, and accept that anger is a very natural emotion.

In conclusion, it is clear that the therapist plays a crucial role in aiding the family of a handicapped child in the successful negotiation of the many emotional hazards facing the child. The present paper has attempted to provide therapists with a working guide to the problems which may beset a handicapped child and his family. In order to assist any family to accept and deal with the child, the therapist must be aware not only of the problems facing the child, but also of herself.

\section{References}

Erikson, E. H. (1955). Childhood and Society. London. Penguin Books.

Freeman, R. D. (1967). Emotional Reactions of Handicapped Children. Rehabilitation Literature, 28, 9.

Hartup, W. W., Glazer, J. A. and Charlesworth, R, Peer (1967). Reinforcement and sociometric status. Child Development, 38, 1017 - 1026.

Rutter, M., Graham, P., Yule, W. (1970). A Neuropsychiatric study in childhood. The Lavenham Press Ltd., Lavenham, Suffolk.

Singer, J. L. (1973). The Child's World of MakeBelieve: Experimental Studies of Imaginative Play. New York. Academic Press.

Singer, J. L. and Singer, D. G. (1976). Imaginative Play and Pretending in early Childhood. In Child Personality and Psychopathology. Ed.: A. Davids. Vol. 3, New York. Wiley and Sons. 